\title{
Rare congenital bleeding disorders
}

\author{
Massimo Franchini ${ }^{1,2}$, Giuseppe Marano ${ }^{1}$, Simonetta Pupella ${ }^{1}$, Stefania Vaglio ${ }^{1}$, Francesca Masiello ${ }^{1}$, Eva \\ Veropalumbo $^{1}$, Vanessa Piccinini ${ }^{1}$, Ilaria Pati ${ }^{1}$, Liviana Catalano ${ }^{1}$, Giancarlo Maria Liumbruno ${ }^{1}$ \\ ${ }^{1}$ Italian National Blood Centre, National Institute of Health, Rome, Italy; ${ }^{2}$ Department of Haematology and Transfusion Medicine, Carlo Poma \\ Hospital, Mantua, Italy \\ Contributions: (I) Conception and design: M Franchini, G Marano; (II) Administrative support: L Catalano; (III) Provision of study materials or \\ patients: M Franchini, G Marano; (IV) Collection and assembly of data: M Franchini, G Marano, S Vaglio, F Masiello, E Veropalumbo, V Piccinini, \\ I Pati; (V) Data analysis and interpretation: M Franchini, G Marano, S Pupella, GM Liumbruno; (VI) Manuscript writing: All authors; (VII) Final \\ approval of manuscript: All authors. \\ Correspondence to: Massimo Franchini, MD. Department of Haematology and Transfusion Medicine, Carlo Poma Hospital, Mantua, Italy. \\ Email: massimo.franchini@asst-mantova.it.
}

\begin{abstract}
The rare congenital bleeding disorders are a heterogeneous group of diseases which include deficiencies of fibrinogen, prothrombin and factors V, V + VIII, VII, X, XI and XIII. They are usually transmitted as autosomal recessive disorders, and the prevalence of the severe forms ranges from one case in 500,000 for factor VII up to one in 2,000,000 for factor XIII in the general population. Patients with rare congenital bleeding disorders may have a broad spectrum of clinical symptoms, ranging from mucocutaneous bleeding to life-threatening haemorrhages, such as those occurring in the central nervous system. The treatment of these disorders is based principally on the replacement of the deficient factor using, when available, specific plasma-derived or recombinant products. The aim of this narrative review is to summarise current knowledge about these rare bleeding conditions.
\end{abstract}

Keywords: Rare bleeding disorders; congenital; treatment; prophylaxis

Submitted Feb 16, 2018. Accepted for publication Aug 23, 2018.

doi: $10.21037 / \mathrm{atm} .2018 .08 .34$

View this article at: http://dx.doi.org/10.21037/atm.2018.08.34

\section{Introduction}

The rare inherited bleeding disorders, usually transmitted in an autosomal recessive manner, account for $3-5 \%$ of all the inherited deficiencies of coagulation factors and include fibrinogen, factor (F) II, FV, FV + FVIII, FVII, FX, FXI and FXIII deficiencies (1-4). Their world distribution is variable, with the prevalence of the presumably homozygous forms in the general population ranging from approximately one case in 2-3 million for FII and FXIII deficiencies (the rarest) to one in 500,000 for FVII deficiency (the most common) (Table 1) (5). Rare bleeding disorders have been described in most populations, with a higher frequency in those in which consanguineous marriages are common (6-8). There are considerable differences in bleeding patterns among patients with rare bleeding disorders but, generally speaking, severe bleeding, such as that involving the central nervous and musculoskeletal systems, appears to be less frequent than in these disorders than in congenital haemophilia $(9,10)$.

Coagulation screening tests, including the activated partial thromboplastin time (APTT), the prothrombin time (PT) and the thrombin time (TT), are the current basis for the laboratory diagnosis of rare congenital bleeding disorders in patients reporting a personal and family history of bleeding (10). In the case of abnormal results of the screening tests, coagulation factor assays should then be performed in order to identify the specific factor deficiency. A subsequent search for mutations of the genes encoding the corresponding coagulation factors may then provide the molecular diagnosis (4). Genetic analysis is also important for antenatal and pre-implantation diagnosis, especially in those countries in which the rates of these rare bleeding disorders and consanguinity are high (10). 
The treatment of rare congenital bleeding disorders is seldom easy, as information from literature on their clinical management is generally scarce and replacement therapy with specific clotting factor concentrates is not always available (11). Dosage and treatment frequency depend on the minimal haemostatic level of the deficient factor that must be achieved, the factor's plasma half-life and the type of bleeding to be treated or prevented. In this narrative review we summarise the main characteristics of each specific coagulation factor defect (Table 1).

\section{Fibrinogen (FI) deficiency}

FI is a $340 \mathrm{kDa}$ glycoprotein that is synthesised in the liver. The plasma concentration of this clotting factor is approximately $1.5-3.5 \mathrm{~g} / \mathrm{L}$ and its half-life is about 4 days. The FI molecule is a homodimer, each half consisting of a trimer of different polypeptide chains named $\mathrm{A} \alpha, \mathrm{B} \beta$ and $\gamma$. The three genes encoding for FI B $\beta(F G B), \mathrm{A} \alpha(F G A)$ and $\gamma(F G G)$, ordered from centromere to telomere, are clustered in a region of approximately 50 kilobases $(\mathrm{kb})$ on chromosome 4. Fibrin is produced by proteolytic cleavage of FI by thrombin with the release of fibrinopeptides A and $\mathrm{B}$ and generation of insoluble fibrin monomers followed by polymerisation (10). FI is also important in primary haemostasis for normal platelet aggregation. Inherited FI disorders are classified according to whether a quantitative deficiency is complete or partial (afibrinogenemia and hypofibrinogenaemia, respectively) or whether there are abnormal circulating molecules without or with an associated true quantitative deficiency (dysfibrinogenaemia or hypodysfibrinogenemia) (12).

Whereas the majority of patients with hypofibrinogenaemia, dysfibrinogenaemia or hypodysfibrinogenemia are usually asymptomatic or have minimal symptoms, afibrinogenemic patients may have a severe bleeding tendency that usually manifests in the neonatal period, with umbilical cord bleeding occurring in $85 \%$ of cases (12). There may also be bleeding in the skin, gastrointestinal tract, genito-urinary tract or the central nervous system. Afibrinogenemic women may experience menometrorrhagia; first-trimester abortions are common and postpartum bleeding is relatively frequent when no prophylactic replacement therapy is given (13). Thromboembolic complications have been reported in afibrinogenemic patients, often independently of replacement therapy, and are probably triggered by excessive thrombin generation (14).

With regards to replacement therapy, three products 
are available: fresh-frozen plasma, cryoprecipitate and FI concentrate (15). This last is the treatment of choice because it is virally inactivated and, therefore, safer than cryoprecipitate or fresh-frozen plasma. The conventional treatment is on-demand, with the FI being administered as soon as possible after the onset of a bleed; however, there are also reports of effective, long-term secondary prophylaxis (especially after central nervous system bleeding) achieved through the administration of FI every $7-14$ days $(15,16)$. Prophylactic treatment appears to be necessary for successful completion of pregnancy: FI replacement must be begun by no later than 5 weeks' gestation to prevent abortion and to maintain FI levels $>100 \mathrm{mg} / \mathrm{dL}$ throughout the pregnancy (a level $>150 \mathrm{mg} / \mathrm{dL}$ is recommended for delivery) (17).

\section{Prothrombin deficiency}

Prothrombin (FII), one of the vitamin K-dependent coagulation factors, is a $72 \mathrm{kDa}$ single-chain glycoprotein that is synthesised in the liver. It requires post-translational carboxylation to become functionally active. Prothrombin consists of four domains, the Gla domain, kringle 1 and kringle 2 domains and a serine protease domain, and is encoded by a gene of approximately $21 \mathrm{~kb}$ located on chromosome 11. FXa activates prothrombin on the surface of platelets in the presence of FV and calcium. During cleavage of prothrombin an activation peptide, fragment $1+2$, is released (18).

Prothrombin deficiency is probably the rarest inherited bleeding disorder since its estimated prevalence is one case in 2 million persons in the general population. Two main phenotypes can be distinguished based on prothrombin activity and antigen level: hypoprothrombinaemia (both activity and antigen levels are concomitantly low) and dysprothrombinaemia (normal or near normal synthesis of a dysfunctional protein) (10).

While a complete FII deficiency appears to be incompatible with life (19), homozygotes with activity levels below $10 \%$ of normal experience severe bleeding manifestations, such as spontaneous haematomas and haemarthroses, intracerebral bleeding, gastrointestinal haemorrhages and gynaecological bleeding (10). Heterozygotes with prothrombin deficiency are usually clinically asymptomatic (18).

Patients with a prothrombin coagulant activity above $20 \%$ usually do not require replacement therapy, but antifibrinolytic agents may be considered. Replacement therapy is needed only in homozygous patients, in the case of bleeding or to ensure adequate prophylaxis prior to surgical interventions. Since there is no prothrombin concentrate, prothrombin complex concentrates are used to treat patients $(11,16,20)$. These concentrates have the advantage, over fresh-frozen plasma, of not carrying the risk of volume overload.

\section{Factor V deficiency}

$\mathrm{FV}$ has a dual role in coagulation: it is a non-enzymatic cofactor required by the prothrombinase complex for the generation of thrombin, but it also contributes to the anticoagulant pathway by down-regulating FVIII activity. FV deficiency may, therefore, result in either a bleeding or thrombotic tendency (21-23). The majority of patients with FV deficiency have concomitant deficiency of FV activity and antigen levels (type I deficiency), but approximately $25 \%$ have normal antigen levels with a dysfunctional protein (type II deficiency). The gene coding for FV is large $(80 \mathrm{~kb})$ and complex (25 exons) and is located on chromosome 1 . This clotting factor is synthesised by hepatocytes and megakaryocytes (24) and, although most $\mathrm{FV}$ is circulating in the plasma, about $20-25 \%$ is present within platelet $\alpha$-granules (24).

Frequent symptoms in patients with FV deficiency are epistaxis and menorrhagia, which occur in approximately $50 \%$ of cases. Other, less frequent symptoms, include haemarthroses and haematomas, which occur in about $25 \%$ of patients. Life-threatening bleeds in the gastrointestinal tract or central nervous system are rare (21). Notably, the bleeding tendency does not correlate well with the FV level, which may be due to the compensation by platelet FV.

$\mathrm{FV}$ can only be replaced through the administration of fresh-frozen plasma, preferably virus-inactivated $(25-28)$, because no FV concentrate is available and FV is not contained in significant amounts in cryoprecipitate or prothrombin complex concentrates (29).

\section{Combined factor V and factor VIII deficiency}

Combined FV and FVIII deficiency is an autosomal recessive bleeding disorder with an incidence of about one case in a million, and is a clinical entity distinct from FV deficiency and FVIII deficiency (5). The molecular mechanism of this association was not understood until 1998 (30), when the combined deficiency was causally associated with mutations in LMAN1 (lectin mannose 
binding protein, previously named ERGIC-53), a gene located on chromosome 18 which codes for a $53 \mathrm{kDa}$ type1 transmembrane protein that acts as a chaperone in the intracellular transport of both factors $(31,32)$. In 2003, another locus associated with the combined deficiency was identified in approximately $15 \%$ of affected families with no mutations in LMAN1: the MCFD2 (multiple coagulation factor deficiency 2), located on chromosome 2. This gene encodes the MCFD2 protein that acts as a cofactor for LMAN1 through the recruitment of correctly folded FV and FVIII in the endoplasmic reticulum $(33,34)$.

Combined FV and FVIII deficiency is characterised by concomitantly low levels (usually $5-20 \%$ ) of both the coagulant activity and antigen of the two coagulation factors. The simultaneous presence of both coagulation defects does not appear to enhance the haemorrhagic tendency observed in subjects with either of the separate defects. The most frequent symptoms, which are usually mild, are easy bruising, epistaxis, and bleeding after dental extractions. Menorrhagia and post-partum bleeding have also been reported in affected women. More severe symptoms, such as haemarthroses and umbilical cord bleeding, are observed very rarely, and gastrointestinal and central nervous system bleeds have been reported in only a few patients. Soft-tissue haematomas are unusual (35).

As there are no FV concentrates available, FV can currently only be replaced through the administration of fresh-frozen plasma, preferably with a virus-inactivated product (36). In contrast, a large number of products that replace FVIII are available: furthermore, the synthetic hormone desmopressin (DDAVP) can be used to raise FVIII levels in minor bleeding episodes.

\section{Factor VII deficiency}

FVII is another vitamin K-dependent glycoprotein of approximately $50 \mathrm{kDa}$. It is synthesised in the liver and encoded by the $F 7$ gene located on chromosome 13. Through its interaction with tissue factor, FVII is fundamental for the initiation of coagulation $(37,38)$. The levels of FVII activity (FVII:C) and antigen (FVII:Ag) in the plasma are affected by a number of genetic and environmental influences ( $F 7$ polymorphisms, gender, age, cholesterol and triglyceride concentrations). FVII deficiency is the most common autosomal recessive coagulation disorder (prevalence of 1 case in 500,000). Most affected patients have concomitantly low levels of FVII:C and FVII:Ag, although some subjects have normal or borderline low levels of FVII:Ag contrasting with lower levels of FVII:C (39).

Symptom severity in FVII deficiency is varied and generally reported to correlate poorly with plasma levels. Some patients do not bleed at all even after major haemostatic challenges. Life- or limb-endangering bleeding is relatively rare, while epistaxis and menorrhagia are the most frequent symptoms (40). The incidence of central nervous system bleeding was found to be high $(16 \%)$ in a series of 75 patients with FVII deficiency (37), but this finding was not replicated in two subsequent large series of Italian and Iranian patients $(41,42)$. Thrombotic episodes (mostly deep vein thrombosis), have been reported in 3-4\% of patients with FVII deficiency, particularly following surgery and during replacement treatment, but spontaneous thrombosis may also occur (43).

A number of therapeutic options can be offered to patients with FVII deficiency, including prothrombin complex concentrates, plasma-derived FVII concentrates, and recombinant FVIIa, which should be considered the optimal replacement therapy, since it can be effective at very low doses $(10-20 \mu \mathrm{g} / \mathrm{Kg})(44)$. The main limitation of this drug is its short half-life. Two or three infusions per week are, therefore, required for regular prophylaxis (45).

\section{Factor $\mathrm{X}$ deficiency}

FX plays a crucial role in the coagulation cascade, since this glycoprotein is the first enzyme in the common pathway of thrombin formation. FX is synthesised mainly in the liver and is encoded by $F 10$, a $22 \mathrm{~kb}$ long gene located on chromosome 13 (46-48). FX deficiency is inherited as an autosomal recessive disorder and the incidence of the severe (homozygous) form is one case per million in the general population. Phenotypically, in FX deficiency the levels of coagulant activity and antigen may both be low, or there may be low coagulant activity with normal or borderline low antigen values (47).

Bleeding in patients with FX deficiency may appear at any age, although those affected more severely (FX:C $<1 \%)$ present early in life with bleeding from the umbilical cord stump. Furthermore, patients with severe deficiencies also commonly have recurrent haemarthroses. The most common bleeding symptoms reported in patients with all levels of severity of FX deficiency are epistaxis and menorrhagia (49-52).

The treatment of patients with FX deficiency is based on the administration of fresh-frozen plasma, prothrombin 
complex concentrates, or a freeze-dried human coagulation FIX/FX concentrate. Recently, a novel high-purity plasmaderived FX concentrate has been developed (16). Even though the concentration of FX rises during pregnancy, women with severe FX deficiency and a history of adverse pregnancy outcomes (e.g., abortion, abruptio placentae or premature labour) may benefit from prophylactic replacement therapy (53).

\section{Factor XI deficiency}

FXI is a dimeric serine protease that is synthesised mainly in the liver. It is encoded by the $23 \mathrm{~kb}$ long $F 11$ gene located on chromosome 4 (54). FXI deficiency is characterised by a decrease of the functional activity of this plasma protein, usually together with correspondingly low levels of FXI:Ag. More rarely, plasma FXI:Ag levels are normal or borderline but there is a dysfunctional form of the protein. The estimated prevalence of severe FXI deficiency in most populations is about $1: 1,000,000$, but the prevalence is reported to be much higher in Ashkenazi Jews, in whom the prevalence of heterozygosity for FXI deficiency is as high as $8 \%(55,56)$.

Bleeding manifestations in FXI deficiency, even in severe cases, are much less predictable than those in haemophilia A or B. The bleeding phenotype is not correlated with the genotype but is related to the site of injury. In cases of injury to a site with high local fibrinolytic activity (e.g., urogenital tract, oral cavity after dental extraction or tonsillectomy), the risk of bleeding is higher (49-67\%) than in sites with less local fibrinolytic activity (1.5-40\%) (57). Patients with severe FXI deficiency (FXI:C $\leq 1 \%$ ) usually have only mild symptoms with bleeding being mainly injury-related. Surprisingly, patients with low but measurable levels of FXI also have mild bleeding, so the clinical phenotypes of these two groups of patients are not strikingly different. This observation, already made for Jewish patients, was recently confirmed in a series of non-Jewish Iranians with severe or moderate FXI deficiency (FXI:C $<1 \%$ to $5 \%$ ) and in subjects with mild deficiency (FXI:C 6\% to 30\%) (58). Females with FXI deficiency are prone to excessive bleeding during menstruation, but case series of women with severe FXI deficiency showed that $70 \%$ of pregnancies were uneventful, even in the absence of prophylaxis $(59,60)$. Patients with alloantibodies that inhibit FXI also do not bleed spontaneously, with manifestations occurring only during surgery or trauma. Patients with inhibitors treated with fresh-frozen plasma or FXI concentrates can have prolonged bleeding following surgery if the inhibitors are not detected prior to surgery and appropriate management instituted (61).

Treatment is based on the administration of antifibrinolytic agents, fresh-frozen plasma, plasma-derived FXI concentrate and recombinant FVIIa, but attention should be given to minimising the risk of complications, such as thrombotic events (especially when FXI concentrates are employed), volume overload, allergic reactions, and the development of inhibitors (54). As patients with severe FXI deficiency can develop excessive and prolonged bleeding following surgery, unless adequately managed, it is recommended that these patients are evaluated carefully prior to surgery, and that the procedure and post-operative period are planned meticulously.

\section{Factor XIII deficiency}

FXIII is the last enzyme to be activated in the coagulation cascade. This transglutaminase crosslinks $\alpha$ - and $\gamma$-fibrin chains, thereby resulting in a stronger clot with greater resistance to fibrinolysis. The factor circulates in the plasma as a heterotetramer of two catalytic A subunits (FXIII-A) and two carrier B subunits (FXIII-B). FXIII-A is produced in cells of bone marrow origin, while FXIII-B is synthesised in the liver. The genes encoding for FXIII-A and FXIII-B are located on chromosomes 6 and 1, respectively. FXIII deficiency, together with prothrombin deficiency, is probably the rarest of the recessively inherited clotting factor deficiencies (estimated prevalence: 1 case in 2,000,000 individuals) $(62,63)$. Plasma levels of FXIII-A, measured as functional activity or immunoreactive protein, are usually extremely low in inherited FXIII deficiency, whereas levels of the FXIII-B subunit are reduced but always remain measurable (62).

Patients with FXIII deficiency usually have a severe haemorrhagic tendency, with early onset of life-threatening symptoms such as umbilical cord bleeding, which occurs in the first few days of life in approximately $80 \%$ of patients, and central nervous system bleeding, which occurs in up to $30 \%$ (64). Bruising, haematomas, delayed wound healing and prolonged bleeding after trauma are also typical. Although less frequent, bleeding into joints and muscles may occur unexpectedly. As far as concerns the mucosa, the most frequent manifestation in a study of a large group of Iranians with severe FXIII deficiency ( $\mathrm{n}=93$ ) was bleeding in the oral cavity (lips, tongue, gums) followed by menorrhagia and epistaxis (65). Twenty percent of women of reproductive 
age had intraperitoneal bleeding that occurred at the time of ovulation, while $50 \%$ of women who became pregnant had at least one miscarriage (65). The same pattern of symptoms was also recently documented by Ivaskevicius et al. who drew on mostly European data in an international registry (66).

Given the clinical severity of the symptoms of FXIII deficiency, regular prophylaxis is advisable (62). This strategy is facilitated by the fact that FXIII levels as low as $2 \%$ to $5 \%$ can provide haemostasis and that the plasma half-life of infused FXIII is very long (11-14 days), so that replacement factor can be infused at long intervals (20-30 days) (67). Monthly prophylactic infusions of FXIII concentrate are necessary during pregnancies to prevent abortions. There are three types of FXIII-containing products: fresh-frozen plasma (preferably virus-inactivated), a plasma-derived, virus-inactivated FXIII concentrate and a new recombinant FXIII-A2 concentrate that contains no human or mammalian proteins $(67,68)$.

\section{Conclusions}

The clinical expression of rare congenital bleeding disorders is extremely variable and both their diagnosis and treatment may be major challenges for physicians. Given the particular complexity of their management, it is important that, once diagnosed, patients with rare inherited bleeding disorders are followed at specialised haemophilia treatment centres. Although considerable knowledge on the prevalence, clinical manifestations and genotypic features of rare inherited bleeding disorders has been acquired in the last decade, additional efforts are needed to raise the level of global care of affected patients. In particular, while further appropriately designed studies are required, national and international registries on congenital bleeding disorders should continue to collect information, since this is crucial for improving the management and, ultimately, the quality of life of these very rare patients (69-71). Finally, pharmaceutical research should devote more effort to increasing the availability and quality of factor concentrates for these disorders.

\section{Acknowledgements}

None.

\section{Footnote}

Conflicts of Interest: The authors have no conflicts of interest to declare.

\section{References}

1. Acharya SS, Coughlin A, Dimichele DM. Rare Bleeding Disorder Registry: deficiencies of factors II, V, VII, X, XIII, fibrinogen and dysfibrinogenemias. J Thromb Haemost 2004;2:248-56.

2. Peyvandi F, Duga S, Akhavan S, et al. Rare coagulation deficiencies. Haemophilia 2002;8:308-21.

3. Peyvandi F, Menegatti M. Rare bleeding disorders: worldwide efforts for classification, diagnosis, and management. Semin Thromb Hemost 2013;39:579-84.

4. Palla R, Peyvandi F. Rare bleeding disorders: diagnosis, and management. Blood 2015;125:2052-61.

5. Peyvandi F, Cattaneo M, Inbal A, et al. Rare bleeding disorders. Haemophilia 2008;14:202-10.

6. Peyvandi F, Palla R, Menegatti M, et al. Introduction: rare bleeding disorders: general aspects of clinical features, diagnosis and management. Semin Thromb Hemost 2009;35:349-55.

7. Bolton-Maggs PH, Perry DJ, Chalmers EA, et al. The rare coagulation disorders--review with guidelines for management from the United Kingdom Haemophilia Centre Doctors' Organisation. Haemophilia 2004;10:593-628.

8. Peyvandi F, Palla R, Menegatti M, et al. Coagulation factor activity and clinical bleeding severity in rare bleeding disorders: results from the European Network of Rare Bleeding Disorders. J Thromb Haemost 2012;10:615-21.

9. Peyvandi F, Di Michele D, Bolton-Maggs PHB, et al. Classification of rare bleeding disorders (RBDs) based on the association between coagulant factor activity and clinical bleeding severity. J Thromb Haemost 2012;10:1938-43.

10. Lippi G, Franchini M, Montagnana M, et al. Inherited disorders of blood coagulation. Ann Med 2012;44:405-18.

11. Keeling D, Tait C, Makris M. Guidelines on the selection and use of therapeutic products to treat hemophilia and other hereditary bleeding disorders. Haemophilia 2008;14:671-84.

12. de Moerloose P, Casini A. Congenital fibrinogen disorders: an update. Semin Thromb Hemost 2013;39:585-95.

13. Kadir R, Chi C, Bolton-Maggs P. Pregnancy and rare bleeding disorders. Haemophilia 2009;15:990-1005.

14. Lak M, Keihani M, Elahi F, et al. Bleeding and thrombosis in 55 patients with inherited afibrinogenaemia. $\mathrm{Br} \mathrm{J}$ Haematol 1999;107:204-6. 
15. de Moerloose P, Neerman-Arbez M. Treatment of congenital fibrinogen disorders. Expert Opin Biol Ther 2008;8:979-92.

16. Peyvandi F, Menegatti M. Treatment of rare factor deficiencies in 2016. Hematology Am Soc Hematol Educ Program 2016;2016:663-9.

17. Kobayashi T, Kanayama N. Prenatal and peripartum management of congenital afibrinogaenemia. Br J Haematol 2000;109:364-6.

18. Lancellotti S, De Cristofaro R. Congenital prothrombin deficiency. Semin Thromb Hemost 2009;35:367-81.

19. Xue J, Wu Q, Westfield LA, et al. Incomplete embryonic lethality and fatal neonatal hemorrhage caused by prothrombin deficiency in mice. Proc Natl Acad Sci USA 1998;95:7603-7.

20. Franchini M, Liumbruno GM, Lanzoni M, et al. Clinical use and the Italian demand for prothrombin complex concentrates. Blood Transfus 2013;11:s94-100.

21. Asselta R, Peyvandi F. Factor V deficiency. Semin Thromb Hemost 2009;35:382-9.

22. Asselta R, Tenchini ML, Duga S. Inherited defects of coagulation factor $\mathrm{V}$ : the hemorrhagic side. J Thromb Haemost 2006;4:26-34.

23. Vos HL. Inherited defects of coagulation factor V: the thrombotic side. J Thromb Haemost 2006;4:35-40.

24. Giampaolo A, Vulcano F, Macioce G, et al. Factor-V expression in platelets from human megakaryocytic culture. Br J Haematol 2005;128:108-11.

25. Cicchetti A, Berrino A, Casini M, et al. Health Technology Assessment of pathogen reduction technologies applied to plasma for clinical use. Blood Transfus 2016;14:287-386.

26. Liumbruno GM, Marano G, Grazzini G, et al. Solvent/ detergent-treated plasma: a tale of 30 years of experience. Expert Rev Hematol 2015;8:367-74.

27. Liumbruno GM, Franchini M. Solvent/detergent plasma: pharmaceutical characteristics and clinical experience. J Thromb Thrombolysis 2015;39:118-28.

28. Liumbruno GM, Sodini ML, Grazzini G.

Recommendations from the Tuscan Transfusion System on the appropriate use of solvent/detergent-inactivated freshfrozen plasma. Blood Transfus 2008;6:25-36.

29. Rocino A, Coppola A. Principles of treatment and update of recommendations for the management of haemophilia and congenital bleeding disorders in Italy. Blood Transfus 2014;12:575-98.

30. Nichols WC, Seligsohn U, Zivelin A, et al. Mutations in the ER-Golgi intermediate compartment protein ERGIC-53 cause combined deficiency of coagulation factors V and VIII. Cell 1998;93:61-70.

31. Neerman-Arbez M, Antonarakis SE, Blouin JL, et al. The locus for combined factor V-factor VIII deficiency (F5F8D) maps to $18 q 21$, between D18S849 and D18S1103. Am J Hum Genet 1997;61:143-50.

32. Nichols WC, Valeri HT, Wheatley MA, et al. ERGIC-53 gene structure and mutation analysis in 19 combined factors V and VIII deficiency families. Blood 1999;93:2261-6.

33. Zhang B, Kaufman RJ, Ginsburg D. LMAN1 and MCFD2 form a cargo receptor complex and interact with coagulation factor VIII in the early secretory pathway. J Biol Chem 2005;280:25881-6.

34. Zhang B, McGee B, Yamaoka JS, et al. Combined deficiency of factor $\mathrm{V}$ and factor VIII is due to mutations in either LMAN1 or MCFD2. Blood 2006;107:1903-7.

35. Peyvandi F, Tuddenham EGD, Akhtari M, et al. Bleeding symptoms in 27 Iranian patients with factor V and VIII combined deficiency. Br J Haematol 1998;100:773-6.

36. Santagostino E, Mancuso ME, Morfini M, et al. Solvent/ detergent plasma for prevention of bleeding in recessively inherited coagulation disorders: dosing, pharmacokinetics and clinical efficacy. Haematologica 2006;91:634-9.

37. Ragni MV, Lewis JH, Spero JA, et al. Factor VII deficiency. Am J Hematol 1981;10:79-88.

38. Mariani G, Bernardi F. Factor VII deficiency. Semin Thromb Hemost 2009;35:400-6.

39. Triplett DA, Brandt JT, Batard MA, et al. Hereditary factor VII deficiency heterogeneity defined by combined functional and immunochemical analysis. Blood 1985;66:1284-7.

40. Mariani G, Herrmann FH, Dolce A, et al. Clinical phenotypes and factor VII genotype in congenital factor VII deficiency. Thromb Haemost 2005;93:481-7.

41. Peyvandi F, Mannucci PM, Asti D, et al. Clinical manifestations in 28 Italian and Iranian patients with severe factor VII deficiency. Haemophilia 1997;3:242-6.

42. Herrmann FH, Wulff K, Auerswald G, et al. Factor VII deficiency: clinical manifestation of 717 subjects from Europe and Latin America with mutations in the factor 7 gene. Haemophilia 2009;15:267-80.

43. Marty S, Barro C, Chatelain B, et al. The paradoxical association between inherited factor VII deficiency and venous thrombosis. Haemophilia 2008;14:564-70.

44. Franchini M, Lippi G. Recombinant activated factor VII: mechanisms of action and current indications. Semin Thromb Hemost 2010;36:485-92.

45. Mumford AD, Ackroyd S, Alikhan R, et al. Guideline for 
the diagnosis and management of the rare coagulation disorders: a United Kingdom Haemophilia Centre Doctors' Organization guideline on behalf of the British Committee for Standards in Haematology. Br J Haematol 2014;167:304-26.

46. Perry DJ. Factor $X$ and its deficiency states. Haemophilia 1997;3:159-72.

47. Uprichard J, Perry DJ. Factor X deficiency. Blood reviews 2002;16:97-110.

48. Menegatti M, Peyvandi F. Factor X deficiency. Semin Thromb Hemost 2009;35:407-15.

49. Herrmann FH, Auerswald G, Ruiz-Saez A, et al. The Greifswald Factor X Deficiency Study Group. Factor X deficiency: clinical manifestation of 102 subjects from Europe and Latin America with mutations in the factor $\mathrm{X}$ gene. Haemophilia 2006;12:479-89.

50. Karimi M, Menegatti M, Afrasiabi A, et al. Phenotype and genotype report on homozygous and heterozygous patients with congenital factor $\mathrm{X}$ deficiency. Haematologica 2008;93:934-8.

51. Peyvandi F, Mannucci PM, Lak M, et al. Congenital factor $\mathrm{X}$ deficiency: spectrum of bleeding symptoms in 32 Iranian patients. Br J Haematol 1998;102:626-8.

52. Lee CA, Chi C, Pavord SR, et al. The obstetric and gynaecological management of women with inherited bleeding disorders - review with guidelines produced by a taskforce of UK Haemophilia Centre Doctors Organization. Haemophilia 2006;12:301-36.

53. Auerswald G. Prophylaxis in rare coagulation disordersfactor X deficiency. Thromb Res 2006;118:S29-31.

54. Duga S, Salomon O. Factor XI deficiency. Semin Thromb Hemost 2009;35:416-25.

55. Bolton-Maggs PH, Wan-Yin B, McGraw A, et al. Inheritance and bleeding in factor XI deficiency. Br J Haematol 1988;69:521-8.

56. Asakai R, Chung D, Davie E, et al. Factor XI deficiency in Ashkenazi Jews in Israel. N Engl J Med 1991;325:153-8.

57. Salomon O, Steinberg DM, Seligshon U. Variable bleeding manifestations characterize different types of surgery in patients with severe factor XI deficiency enabling parsimonious use of replacement therapy. Haemophilia 2006;12:490-3.

Cite this article as: Franchini M, Marano G, Pupella S, Vaglio S, Masiello F, Veropalumbo E, Piccinini V, Pati I, Catalano L, Liumbruno GM. Rare congenital bleeding disorders. Ann Transl Med 2018;6(17):331. doi: 10.21037/atm.2018.08.34
58. Peyvandi F, Lak M, Mannucci PM. Factor XI deficiency in Iranians: its clinical manifestations in comparison with those of classic hemophilia. Haematologica 2002;87:512-4.

59. Myers B, Pavord S, Kean L, et al. Pregnancy outcome in factor XI deficiency: incidence of miscarriage, antenatal and postnatal haemorrhage in 33 women with factor XI deficiency. BJOG 2007;114:643-6.

60. Salomon O, Steinberg DM, Tamarin I, et al. Plasma replacement therapy during labor is not mandatory for women with severe factor XI deficiency. Blood Coagul Fibrinolysis 2005;16:37-41.

61. Salomon O, Zivelin A, Livnat T, et al. Prevalence, causes and characterization of factor XI inhibitors in patients with factor XI deficiency. Blood 2003;101:4783-8.

62. Karimi M, Bereczky Z, Cohan N, et al. Factor XIII deficiency. Semin Thromb Hemost 2009;35:426-38.

63. Ichinose A. Physiopathology and regulation of factor XIII. Thromb Haemost 2001;86:57-65.

64. Anwar R. Factor XIII deficiency. Br J Haematol 1999;107:468-84.

65. Lak M, Peyvandi F, Ali Sharifian A, et al. Pattern of symptoms in 93 Iranian patients with severe factor XIII deficiency. J Thromb Haemost 2003;1:1852-3.

66. Ivaskevicius V, Seitz R, Kohler HP, et al. International registry on factor XIII deficiency: a basis formed mostly on European data. Thromb Haemost 2007;97:914-21.

67. Gootenberg JE. Factor concentrates for the treatment of factor XIII deficiency. Curr Opin Hematol 1998;5:372-5.

68. Lovejoy AE, Reynolds TC, Visich JE, et al. Safety and pharmacokinetics of recombinant factor XIII-A2 administration in patients with congenital factor XIII deficiency. Blood 2006;108:57-62.

69. Hassan HJ, Morfini M, Taruscio D, et al. Current status of Italian Registries on inherited bleeding disorders. Blood Transfus 2014;12:s576-81.

70. Soucie JM, McAlister S, McClellan A, et al. The universal data collection surveillance system for rare bleeding disorders. Am J Prev Med 2010;38:S475-81.

71. Makris M, Calizzani G, Fischer K, et al. EUHASS: The European Haemophilia Safety Surveillance system. Thromb Res 2011;127:S22-5. 